\title{
Hand tool project requirements: the case of banana cultivation and its physical demands (OWAS)'
}

\author{
Letícia Takayama ${ }^{a}$, Giselle Schmidt Alves Diaz Merino, ${ }^{a, b}$ Eugenio Andrés Díaz Merino ${ }^{a}$ Lucas José Garcia ${ }^{a}$, \\ Julia Marina Cunha ${ }^{a}$, Susana Cristina Domenech ${ }^{b}$ \\ Universidade Federal de Santa Catarina \\ buniversidade do Estado de Santa Catarina \\ e-mails: takayamaleticia@gmail.com; gisellemerino@gmail.com; eugenio.merino@ufsc.br; \\ lucasjose@gmail.com; juliamarinac@gmail.com; scdomenech@gmail.com
}

\begin{abstract}
The cultivation of bananas presents several activities aiming the product processing. Some of these activities are a physical burden to workers, especially to their upper limbs. Therefore, this project analyzed the banana tumbling with the purpose of identifying the critical aspects and, consequently, defining the requirements for re-designing the tools used. Data was obtained by site visit, interviews, and photographs complemented with the use of OWAS posture record. The results allowed the identification of critical issues and the definition of requirements such as change to the tool angle and its handle permitted the adoption of a less sacrificing posture which impacted more positively the workers production performance.
\end{abstract}

Keywords: design, design requirements, hand tool, banana, OWAS.

\section{Introduction}

According to the International Ergonomics Association (2000), it is ergonomics role to contribute towards the evaluation of tasks, tools, systems and environments of work to make them compatible with people's needs, skills and limits. The application of ergonomics in agriculture is something new when compared with the one used in industry, because it is considered a non-structured activity. The work accomplished by farmers is usually hard and leads to unconventional body postures, excessive muscle strain, repetitive use of equipment and unfavourable environment conditions (IIDA, 2005). A great part of injuries in agriculture is due to the risks run in the work environment with the equipment used and the adverse conditions of the task. The agricultural activity also requires loads of work that can harm the worker's body cause health problems due to the physical exhaustion and to an increased rate of mistakes (MONTEIRO, 2004). One of the main problems for agriculture workers relates to bad posture and to the wrong use of tools and equipment, which tends to cause backache, fatigue, accidents and occupational diseases leading to acute chronic problems (FLEMING, 2003).

\footnotetext{
${ }^{1}$ Enhanced version of an article previously published in the proceedings of IDEMI 2015 (IV Conferência Internacional de Design, Engenharia e Gestão para a Inovação)
}

Ergonomic measures applied to workstations can reduce the workers' biomechanical and cognitive demands. A few examples of measures taken to promote biomechanical balance and reduce health damages are: eliminating tasks that are far too repetitive and adaptation of machines, equipment and materials (IIDA, 2005).

Specifically in the production of bananas there is also discrepancy in studies and on the enforcement of ergonomic improvement towards reducing harm to the health of the workers.

Nowadays the cultivation of bananas is one of the main international businesses in the tropical and subtropical regions of the world (SILVA NETO; GUIMARÃES, 2011). According to Empresa Brasileira de Pesquisa Agropecuária (2013), Brazil is the fifth main producer of banana in the world, with $6,902,184$ tons produced in 2012, which is the equivalent to $6.8 \%$ of the world production.

Banana (Musa spp.) is one of the most consumed fruits in the world and its cultivation is carried out in over 130 countries. Apart from the fruit, the heart and the inside of its trunk is also edible and its fibre can be used for the production of top quality cloth and paper (ARAGUAIA, 2014). Banana is a fragile fruit which requires great amounts of care to harvest and also after it has been harvested, two phases in production that require 
a great amount of strength and precision from the workers (BORGES et al., 2014).

The present article has for purpose the analysis of posture constraints related to the extraction of banana bunches, a stage that occurs after harvest, and to the definition of requirements for re-designing the manual tool used, with emphasis on ergonomics in order to have a positive impact on health and productivity.

\section{After harvesting the bananas}

In order to better understand the extraction of the banana bunches, universe of the research, it is necessary to approach the other stages of the after-harvest process in order to understand the course of the banana up to the moment when bunches are extracted.

After cropped, the bunch of banana is carefully transported to the packaging house with the use of cableway, wheelbarrow, and cart or on cushioned pillows over the workers shoulders. In order to avoid damage to the bunches (bumps, falls, pressure and friction), transportation is done carefully with the use of cushioned surfaces, protective materials and gentle accommodation of the bunches into the carts. In the packaging house, various processes, such as pistil removal, extraction of the bunch, arrangement into bouquets, washing, classification, weighing, anti-fungi treatment, quality stamp sticking and the packaging of the fruit are carried out. The bunches are hung with hooks in the shade after they arrive to the packaging house. The first stage of the process is withdrawal of scrap (ill-formed fruit, rotten fruit, pieces of leaf or other material stuck to the bunch) and the removal of pistils from the bunch (removal of floral remains from the tips of the bananas). The extraction is the removal of the pack of bananas from the peduncle (stalk that supports and holds the bunch of bananas). For that to be carried out, the bunches of banana are hung with hooks, by the peduncle, to make the separating cut from the bunch easier, a cut which is carried out at the rachis (common axis uniting all of the bananas). Each cut separates only one pack of bananas from the peduncle and, in that way, such movement is undertaken repeatedly a number of times during the workday, putting the workers' health at an increased risk. The tool for the extraction of packs of banana under analysis (Figure 1) is a model widely used on the cultivation of bananas in Brazil. Its formal characteristics are with the edge of the blade turned downwards, it's length is in a bow, the extension of the grip upwards at an angle of $30^{\circ}$ and a handle in the same direction as the extension. The banana bunches are removed downwards by fixing the tool in the gap between the banana packs and then twisting it so that the axis can be cut (BORGES et al., 2014).

After the extraction of the banana packs, these packs are placed in washing tanks so that dirt can come off and the cuts can heal. The fruits are removed from this tank and go

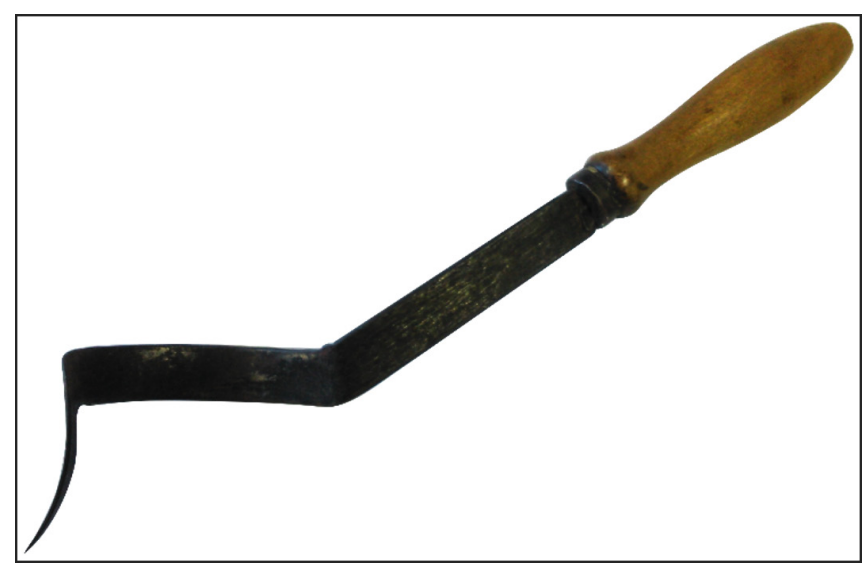

Figure 1. Banana tumbling tool. Source: The authors.

to our subdivision process, where each pack is divided into bouquets, composed of two up to nine sets of united bananas, in order to make product packaging easier. The bouquets need to be sorted, weighed and labelled correctly, so as to guarantee the fruit quality. After this stage, the fruits are placed carefully inside cardboard or plastic boxes, lined inside with plastic for protection against an excessive loss of water or friction (BORGES et al., 2014).

\section{Handling the tool for the extraction of bunches}

Handling the tool for the extraction of bunches is an activity that has been based on Iida studies (IIDA, 2005). It is considered a movement of control performed by the human body in order to imply some amount of energy to the object. The ways of handling it can vary according to the strength applied, to the speed and precision thanks to the great mobility of the opposing thumb. In the case of the extraction knife, the handling is rough because it is performed with the centre of the hand. In this case the fingers' task is holding the tool, they are kept still while the fist and the arm move. The rough handling, in general, implies a greater strength and less precision when compared to a fine handling. The power of the rough handgrip, when all of the fingers close around the object, can be up to $40 \mathrm{~kg}$.

The movements carried out while the tool is being used relate to the articulations of the upper limb, specifically: elbow, shoulder, and wrist.

\section{Biomechanics of the upper limb}

The human hand is operating tool for the upper limb and favours the performance of various functions, thanks to prehension. The hand, the fist and the fingers allow manipulation activities through a number of postures (KAPANDJI, 2000). Most muscles in the articulations of wrist, hand and fingers have their origin in the elbow, and that is why injuries in such areas can have consequences in other parts of the body (HAMILL; KNUTZEN, 2012). 
The hand has a great number of joints to perform movements. Those joints are named carpometacarpal, intermetacarpal, metacarpophalangeal and interphalangeal. The carpometacarpal joint of the thumb allows a wide range of movements, while for the second up to the fourth carpometacarpal joints movement is reduced due to the presence of ligament contention. Flexion, extension, finger abduction (when the other fingers are moved away from the middle finger), adduction (when the other fingers are moved close to the middle finger) movements and circumduction from the second to the fifth finger are responsible for the metacarpophalangeal articulation (HALL, 2009).

Hand strength is something associated with the power of prehension to hold objects. The prehension that produces the most power is the one undertaken with a closed fist, when all three joints (intermetacarpal, metacarpophalangeal and interphalangeal) are flexed. Wrist position also interferes with an increase in prehension, however it increases the incidence of tension and compression of areas adjacent to the wrist. Thus, the neutral position of the wrist is more appropriate and secure for reduced injury to the structures in the wrist (HAMILL; KNUTZEN, 2012).

The wrist is the distal articulated joint of the upper part of the body and it guides the hand to a better prehension position by means of rotating movements and the sagittal and frontal planes. The rotating movement of the wrist named circumduction is defined as the combination of flexion-extension and abduction-adduction movements. Such movement occurs simultaneously in both axis of this articulated joint (KAPANDJI, 2000).

Flexion and extension (Figure 2) are movements of the wrist in the sagittal plane. Flexion relates to the movement of the palm surface towards the foreface of the forearm. Extension, on the other hand, is bringing the hand back to a neutral position, a movement contrary to that of the flexion, which is to say the dorsal surface of the hand approaches the back of the forearm. The abduction and adduction movements (Figure 3) are undertaken on the frontal plane. Abduction is characterized as a movement of the hand towards the side of the thumb, while movement in the other direction is called adduction (HALL, 2009).

The elbow is the intermediate joint of the upper limb and it unites its first and second segments: arm and forearm. It is the elbow role to stretch and dislodge the hand, which is the active end of the upper limb to a more or less distant position, on the three planes. Together with the arm, the elbow constitutes a compass allowing the hand to approach the shoulder and the mouth (KAPANDJI, 2000).

A few movements performed by the elbow are flexion and extension. For the movement of flexion the shoulder diminishes the angle between arm and forearm, while the movement of extension the opposite occurs. The rotating movement of the forearm around its longitudinal axis is

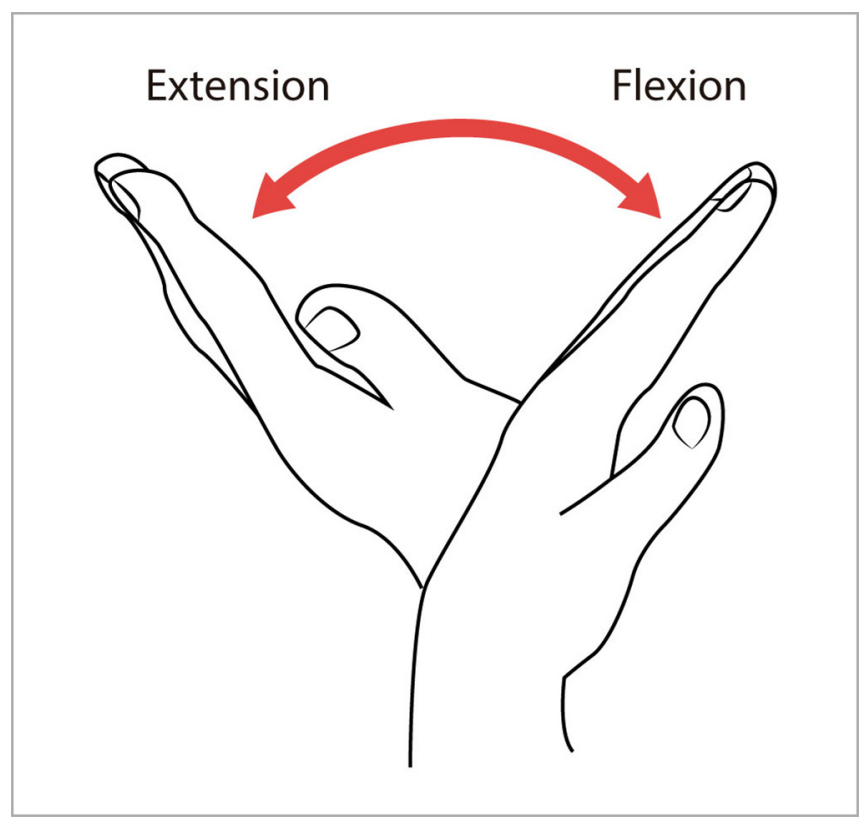

Figure 2. Flexion and extension movements of the wrist joint. Source: Adapted from Hall (2009, p. 213).

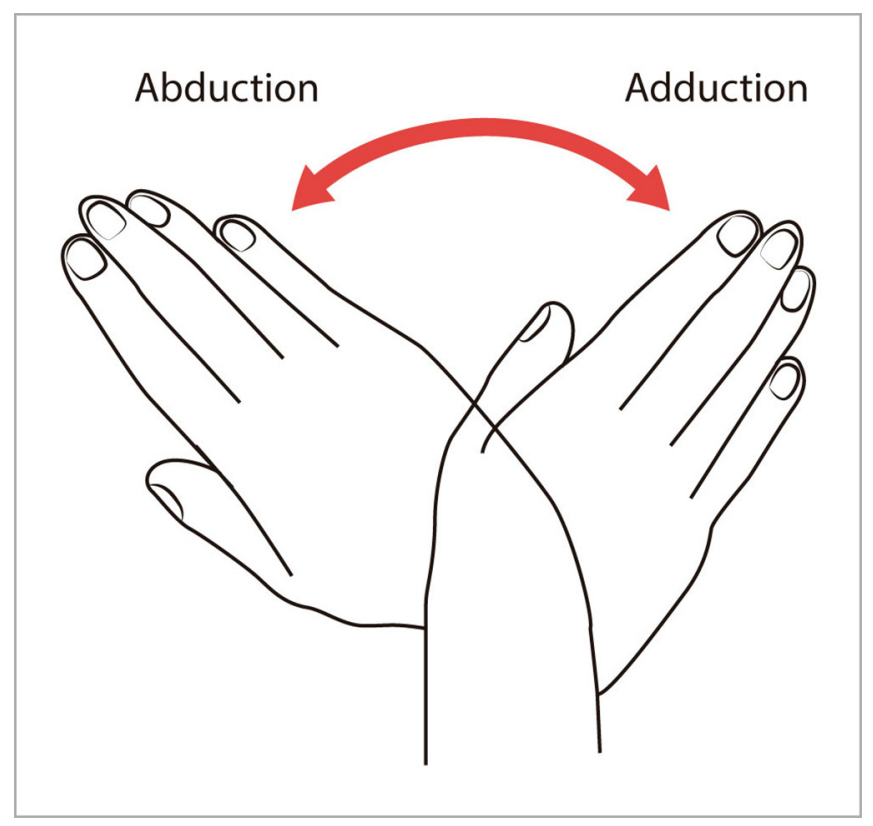

Figure 3. Abduction and adduction movements of the wrist joint. Source: Adapted from Hall (2009, p. 213).

named pronation-supination. Such movements only can be analysed when the elbow is flexed at a $90^{\circ}$ angle next to the body. The position of supination of the elbow is carried out when the ha is turned up with the thumb turned outwards, whereas on the pronation position the palm of the hand is turned down and the thumb inwards (KAPANDJI, 2000).

The shoulder is considered the most mobile articulated joint in the human body, for it has three main axis allowing guidance for the upper limb on the three planes of the spread 
and are known as: transverse, anteroposterior and vertical. The transverse axis allows the movements of flexion (a wide movement, $180^{\circ}$ forward) and extension (movement of scarce amplitude, $45^{\circ}$ to $50^{\circ}$ backwards) in the sagittal plane. The anteroposterior axis allows movements of abduction (upper limb gets away from the symmetry plane) and adduction (upper limb approaches the symmetry plane). At last, the vertical axis is determined by the intersection of the frontal and sagittal plane and also plays a fundamental role on the flexion-extension of the elbow. Rotation of the arm happens on the longitudinal axis at any position of the shoulder (KAPANDJI, 2000).

\section{Material and methods}

This research is a case study applied in nature, in order to raise quantitative data relating to the postures of a specific type of worker by means of direct observation documented by photographs and video through the OWAS system. The field study focused on the analysis of movements of the upper limb of a worker in banana cultures on the activity of extracting the banana packs from the peduncle. The research was of fundamental importance to get information that have been little investigated with regards to the damages caused by the use of extraction tools, in order to create ergonomic improvement for this product.

Authors such as Kapandji (2000), Iida (2005), Hall (2009), Hamill and Knutzen (2012) and Dreyfuss (2005) have guided the analysis of postures and articulation movements while the banana extraction activities for this research happened.

In order to identify the workers' posture during the extraction activities, the OWAS system (Ovako Working Posture Analysing System) was used. This system of posture recording was developed in 1977 by three Finnish researchers (Karku, Kansi and Kuorinka), who found 72 postures typically adopted by workers in heavy industry. From these postures several combinations of dorsal (4 positions), arms (3 positions) and legs ( 7 positions) positions have resulted. In the OWAS system postures are sorted out in the following way: class 1 (normal posture, dispensing any care); class 2 (posture must be checked on the following routine review); class 3 (posture deserving attention in the short term) and class 4 (posture needing immediate attention). Classes of posture are displayed in Table 1, which shows the results from the combination of variables regarding back, arm and leg (IIDA, 2005)

\subsection{Data collection}

The data have been collected through observation videoed in a cooperative producer of bananas, Cooper Rio Novo, in Corupá-SC. The system OWAS was applied from the videos of the task during harvest. The types of banana analysed during the harvest were of the kinds prata and caturra, also known as nanica. The videos were captured from a front, top and right side perspective. It is necessary to highlight that only one male individual took part in the harvest, because he was the one responsible for the extraction task in that cooperative producer of bananas. In that way, this individual is in charge of the whole production and he repeats the extraction task several times a day which can lead to posture constraints and injuries because of the repetition.

\subsection{Data analysis}

An analysis of the data related to the application of the OWAS system and the study of articulation movements of the upper limb. The analysis was carried out from the observation of videos on the extraction, with speed reduced 0.125 times, in order to optimize the capture of movements of the upper limb during activity. The study was based on posture identification with the OWAS system, as much as on the analysis of the movements of articulations of the upper limbs, which also interfere with the extraction activity.

Generally, on the stage of extraction, the worker keeps himself standing with his back inclined and slightly twisted. Most of the time his arms are downwards in constant movement and eventually these limbs are positioned upwards. The legs, on their turn, are kept straight in the beginning of the activity, and they tend to bend for the extraction of the lower packs of banana. During the activity, there is the bending of the wrist (movement bringing the forefaces of the hand and forearm close to each other) when the user of the tool carries out the separation cut, and the wrist is extended (a movement that brings the back side of the hand and of the forearm close to each other) when it returns to the normal holding position. During this stage, when the bunch stem is cut, there is a medial rotation of the shoulder.

In order to better analyse the movements in all of the phases of extraction, this task was divided into four parts corresponding to the cutting of the higher, medial, lower packs of banana and those that are left. Analysis of the articulation joints of the upper limb were carried out through illustrations (Figure 4) showing their work in a simple way from a frontal, top and right-side perspective. To help an understanding the movements in the illustration, subtitles were created with the symbols used and their respective meanings, present in Figure 5.

The first part analysed comprises the cutting of the higher packs of bananas. In relation to posture, in this stage, the worker has his back slightly inclined and twisted, one arm raised and both legs straight. According to Table 1, mentioned above, the cutting of higher packs is sorted as class 3 , which is to say it deserves attention in the short term. 


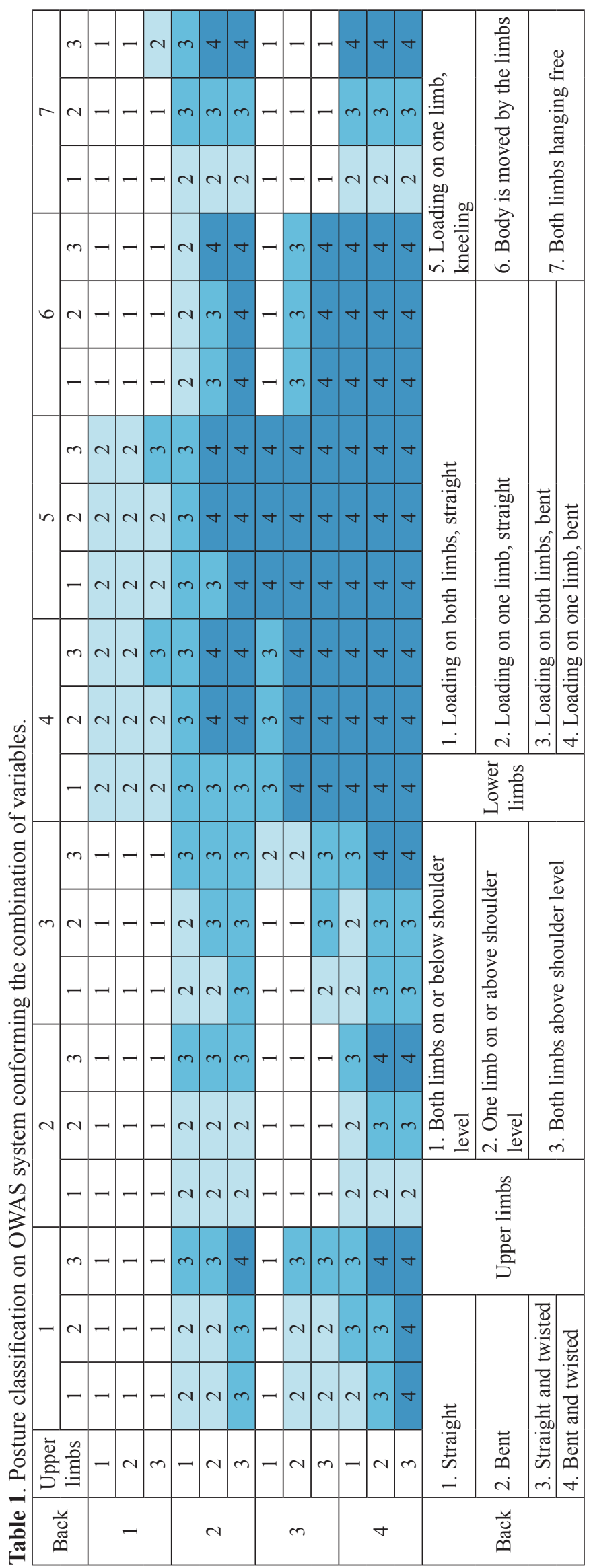


Because the upper limb holding the tool is raised, the articulations of the shoulder, elbow and wrist bend more than at other stages of the task. During the extraction of the higher packs there is the medial rotation of the shoulder, in other words, the shoulder makes the inwards rotation

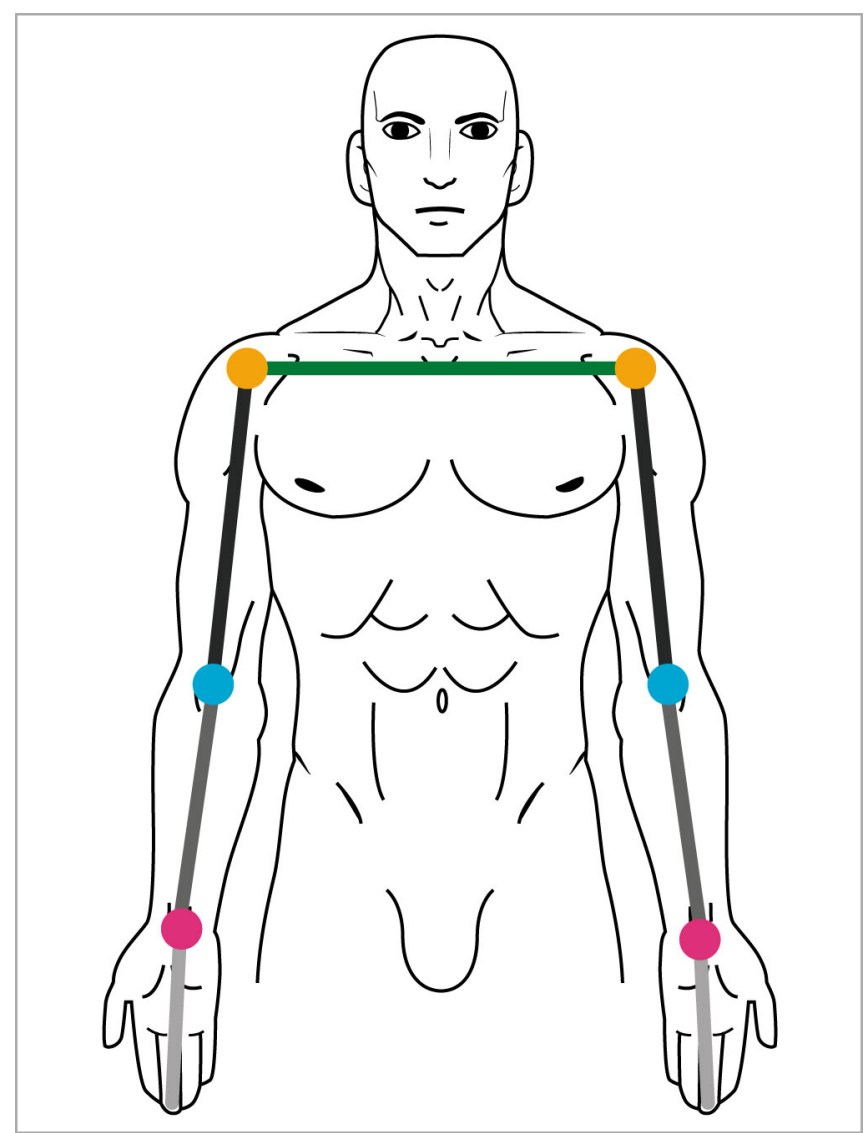

Figure 4. Upper limb joints illustration. Source: The authors.

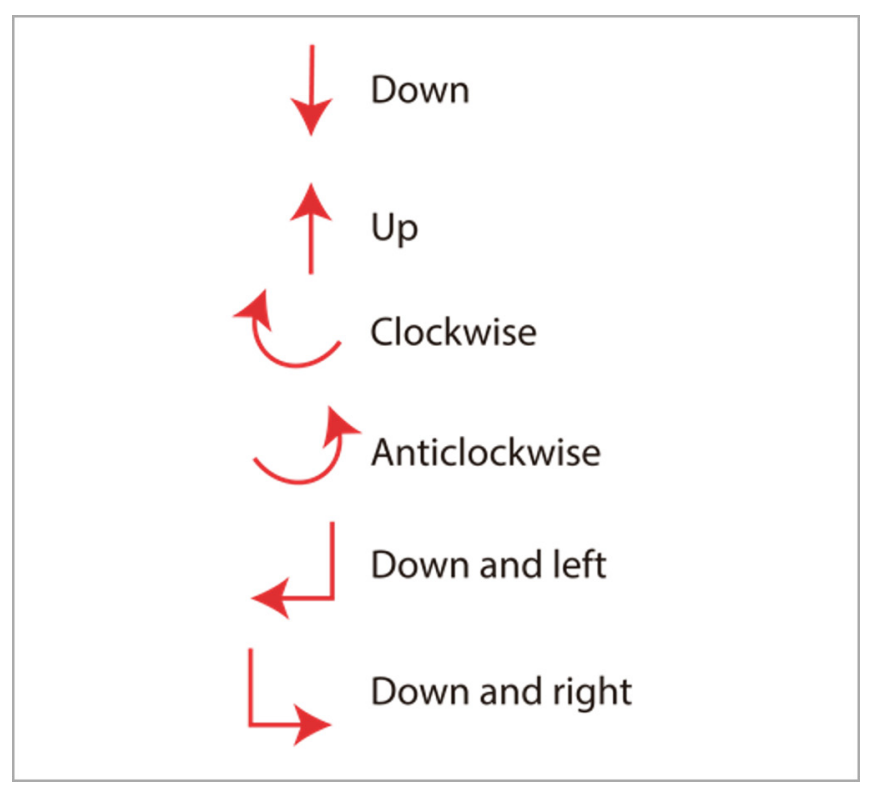

Figure 5. Symbols used on the illustrations. Source: The authors. movement, clockwise. Whereas the elbow lowers and moves towards the back of the body in order to cut the bunch stem and it returns, sideways, to the midline, which is called adduction. The wrist articulation also makes the movement downwards and ends this stage rotating clockwise. The movements for the extraction of the higher packs of bananas can be seen in Figure 6 and its illustrated analysis corresponds to Figure 7, where it can be seen from a frontal, top and right side perspective.

For the extraction of the middle height packs, the user stands in a better position for cutting the bunch stem because the upper limb commanding the tool can have a fine reach of the pack, without requiring an excessive raising or lowering. In this posture, the worker is with his back inclined and slightly twisted, arms downwards in movement and legs slightly flexed. In the OWAS system, this posture is of class 2 , which is to say, it is a posture that offers little risk and that must be checked on a future review of the activity.

For cutting the banana packs from the middle of the bunch, the articulation of the shoulder rotates clockwise; the elbow also rotates in order to move to the back part of the body, the wrist rotates and also bends and extends. The movements carried out for the extraction of the packs of banana in the middle of the bunch can be seen in Figure 8 and its analysis corresponds to Figure 9, showing it on the front, top and right side planes.

As for the extraction of the lower packs, the arm is more stretched and the worker needs to bend down, also bending his body and knees in order to carry out the cutting. On this stage, the worker's back is inclined and twisted, his arms are downwards and both legs are flexed. According to the OWAS system, this posture is of class 3 and deserves attention in the short term. For the cutting of the lower packs the shoulder joint articulation rotates clockwise, the elbow rotates and the wrist flexes and extends. The movements for cutting the lower packs can be seen in Figure 10 and its analysis corresponds to Figure 11, showing the front, top and right side planes.

The cutting of the final pack of bananas is carried out in a different way in relation to the other packs. The peduncle is taken near the cleaning tank and the last pack of bananas is laid on the edge of this tank in order to be cut, which is carried out from below. The worker's posture in this stage is with his back bent down, one arm raised and both legs slightly flexed. In the OWAS system this position is class 3 and deserves surveillance.

Separation of the last pack happens with a movement of adduction of the shoulder, elbow rotation and wrist rotation, flexion and extension. The movements for extraction of the final packs can be seen in Figure 12, and its analysis corresponds to Figure 13, which shows the front, top and right side planes. 


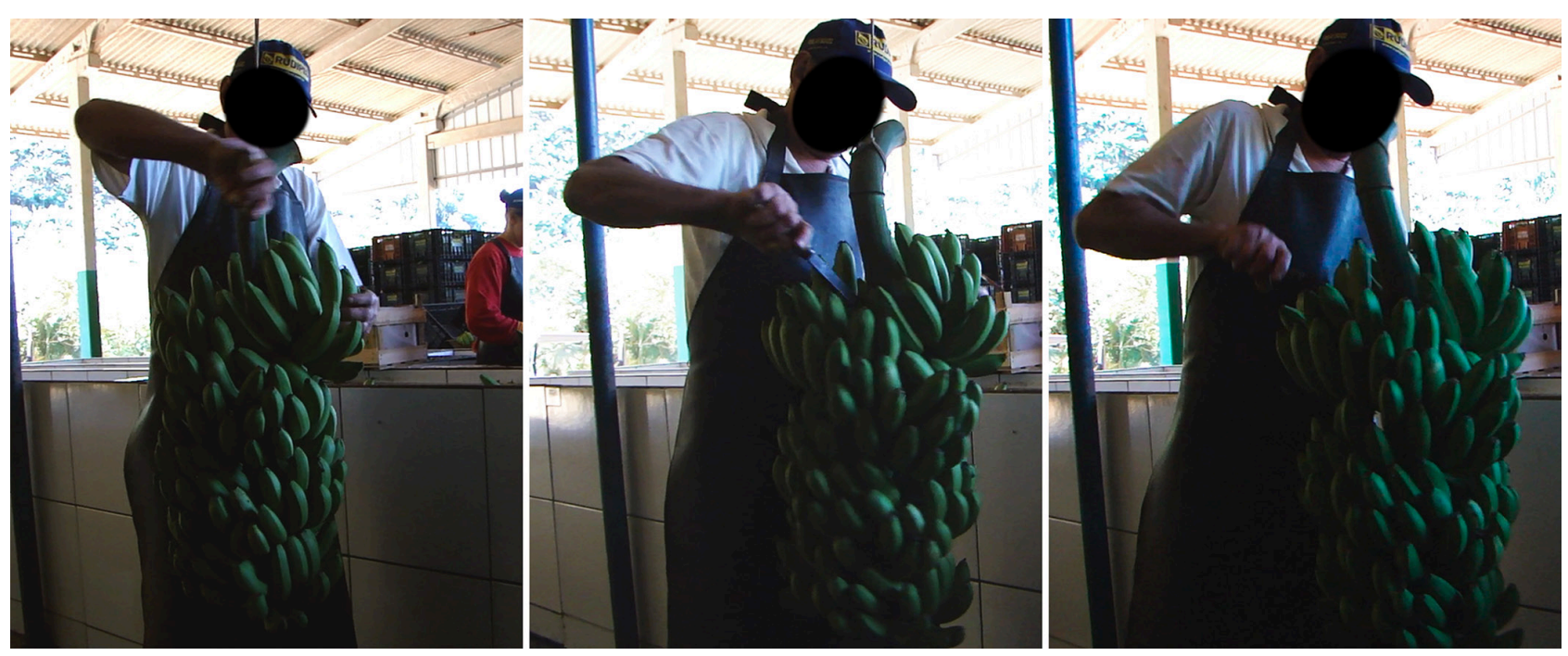

Figure 6. Movements for the extraction of the higher packs of bananas. Source: The authors.

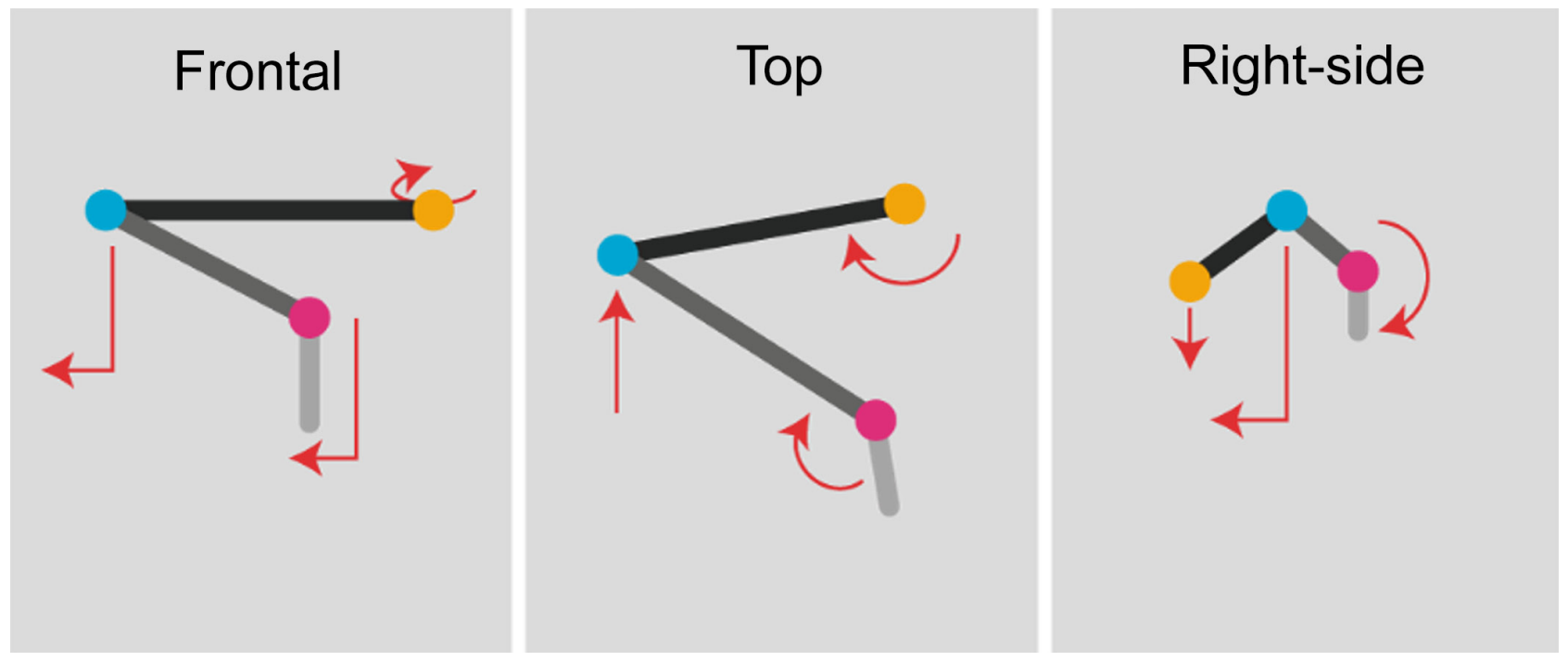

Figure 7. Movements analysis for the extraction of the higher packs of bananas from a frontal, top and right side perspective. Source: The authors.

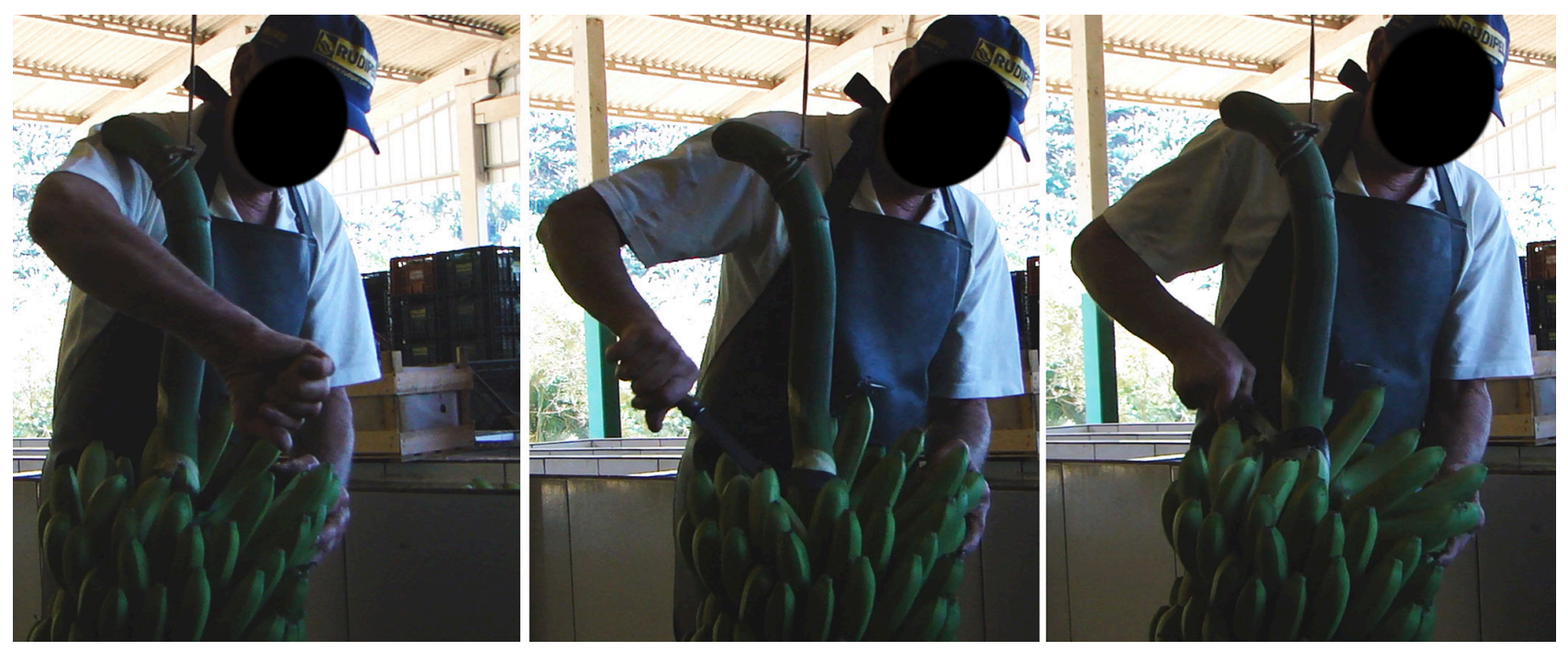

Figure 8. The movements for the extraction of the packs of banana in the middle of the bunch. Source: The authors. 

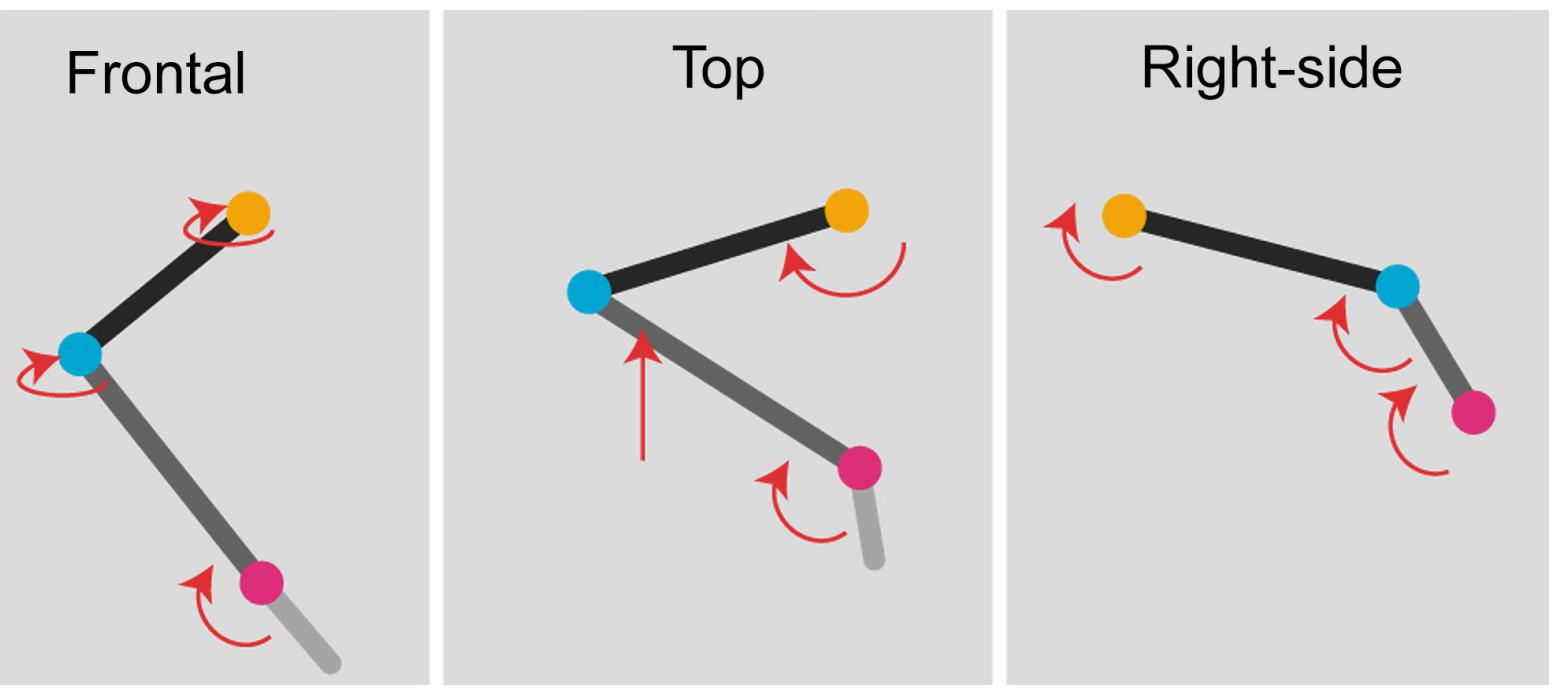

Figure 9. Movements analysis for the extraction of the packs of banana in the middle of the bunch from a frontal, top and right side perspective. Source: The authors.
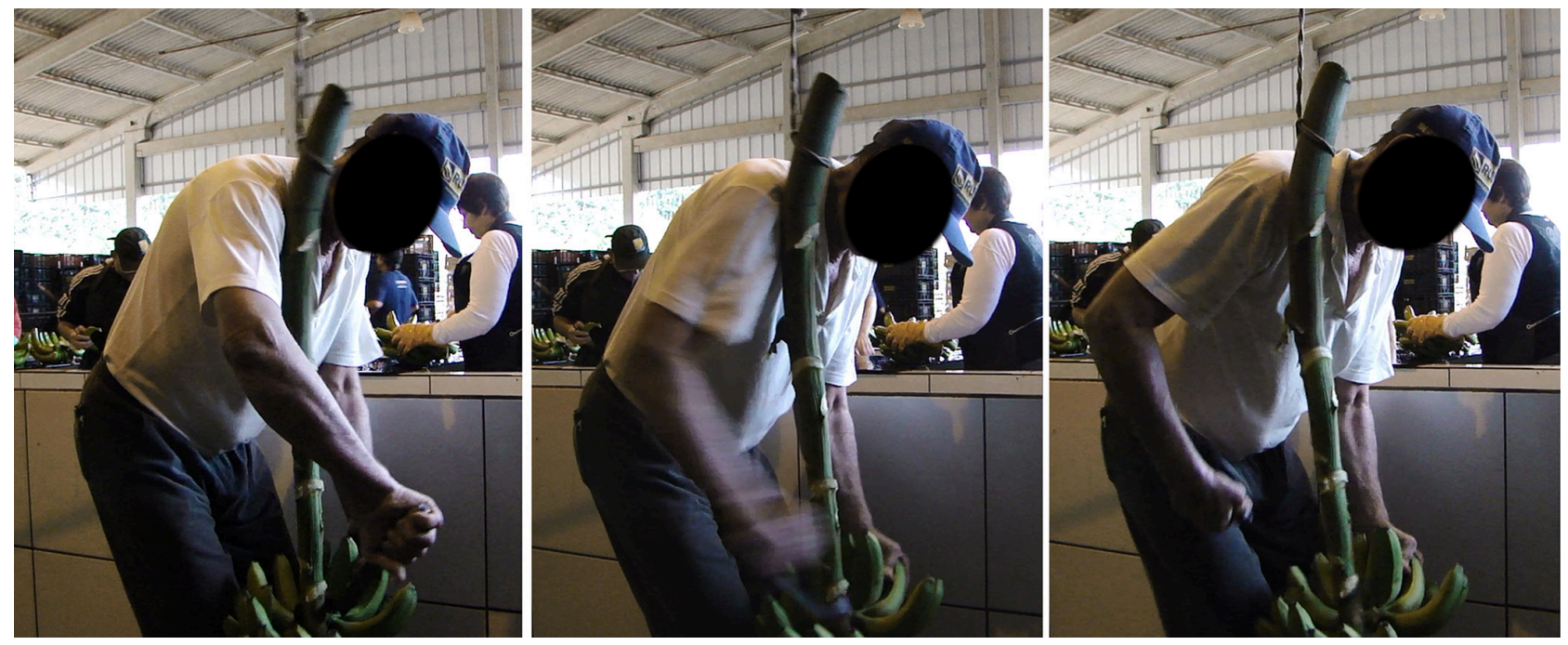

Figure 10. Movements for cutting the lower packs. Source: The authors.
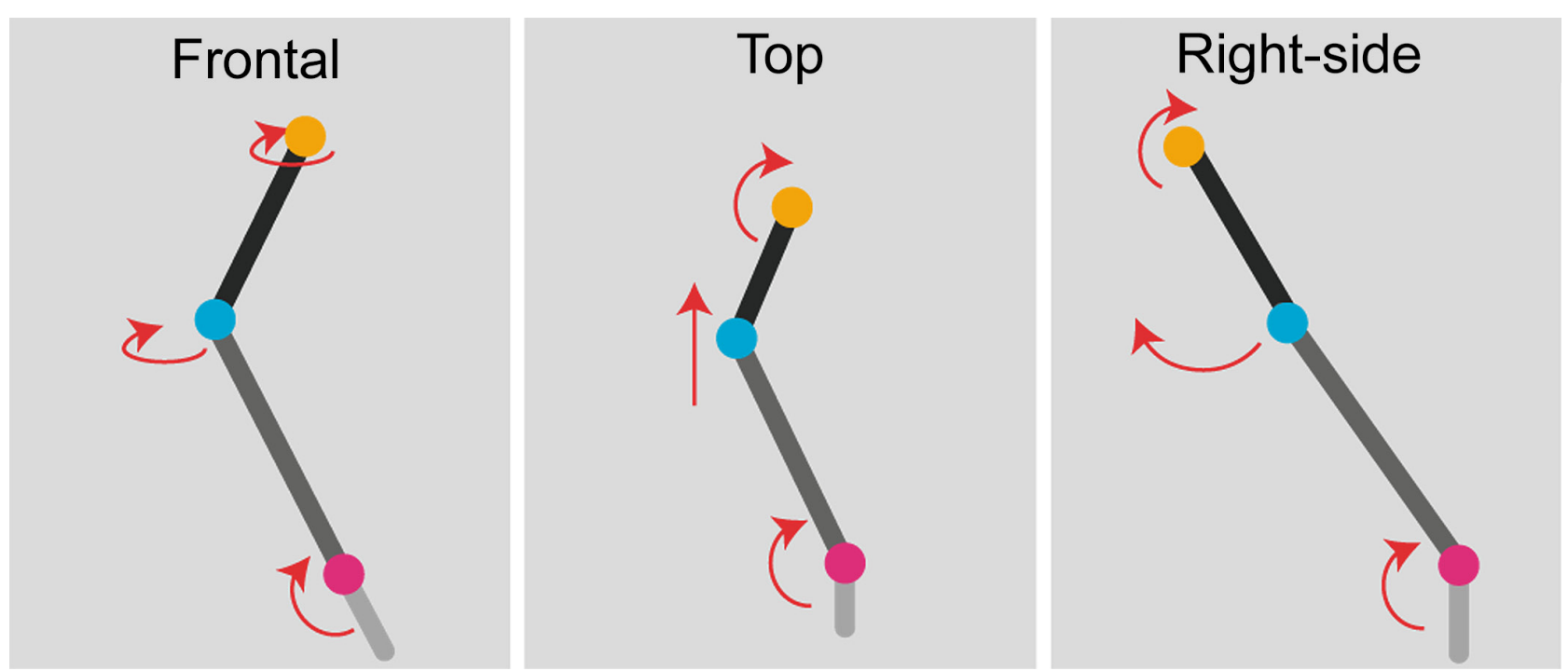

Figure 11. Movements analysis for cutting the lower packs from a frontal, top and right side perspective. Source: The authors. 

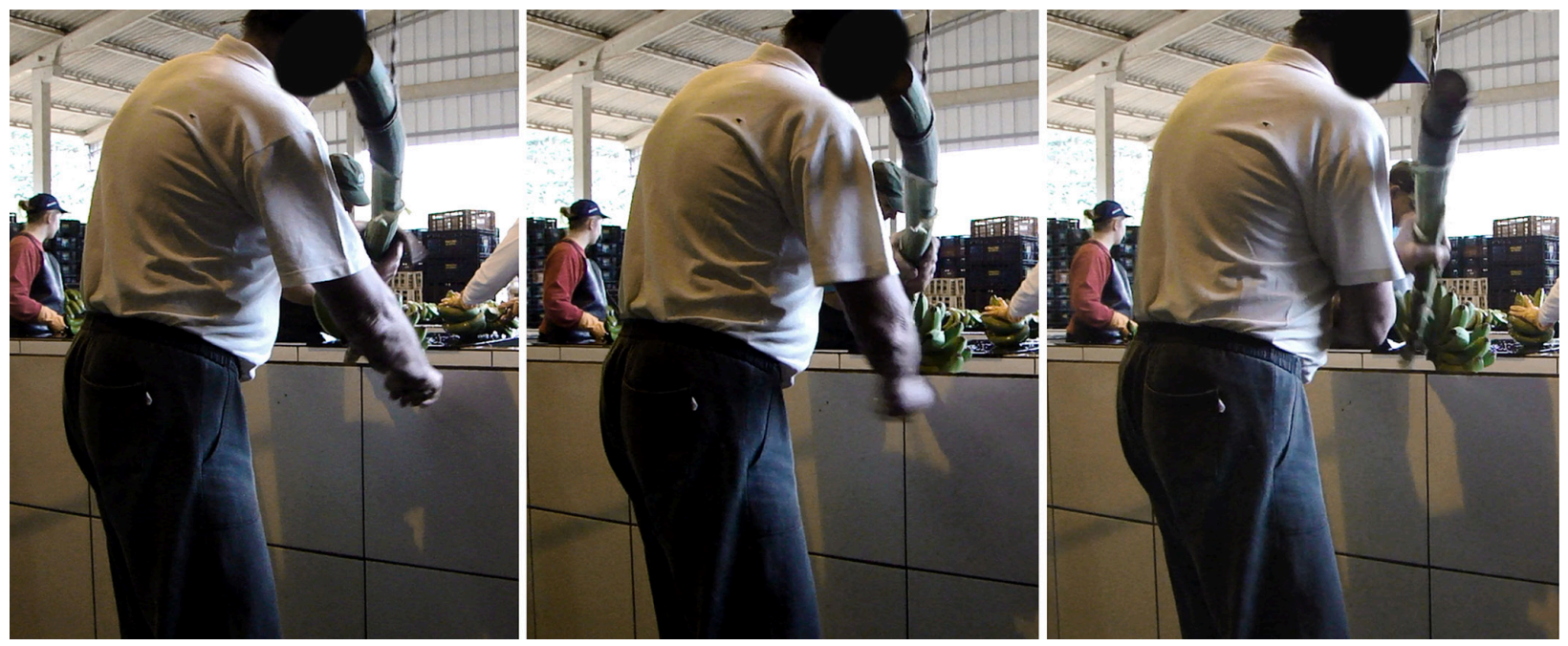

Figure 12. The movements for extraction of the final packs. Source: The authors.
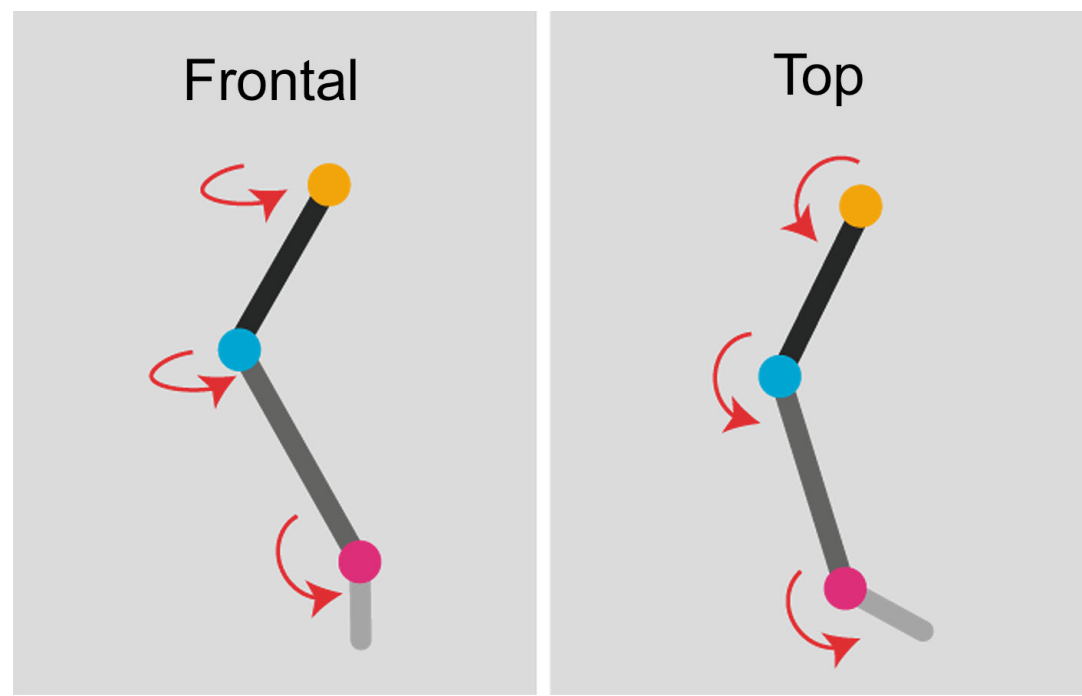

\section{Right-side}

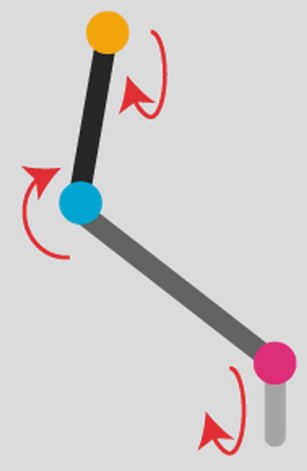

Figure 13. Movements analysis for cutting the final packs from a frontal, top and right side perspective. Source: The authors.

\section{Results}

The result of the data analysis has showed that the extraction activity of the banana packs with the tool used provokes inappropriate postures and excessive torsion, flexion and extension of the upper limb, legs and back articulations. The cutting of the packs at both ends of the bunch was what showed to have the greatest posture risk, with results of class 3 in the OWAS system, for the inordinate raising and bending of the upper limb. As for packs in the lower end of the bunch, flexion of the back and of the inferior limbs has been noticed, in order to reach the pack for cutting. The fruits in the middle of the bunch were extracted in a more efficiently way and required less injuring postures of class 2, because of the position for reaching the pack as much as the size of the knife. Although more aggravating postures, those of class 4 , were not present in the analysis, intense repetition of the task tends to aggravate postures of class 3 and 2 .

Guidelines related to posture were defined according to the activity demand, by means of anthropometric measurements and ergonomic recommendations presented by Iida (2005) and Dreyfuss (2005):

I. It is recommended that pack extraction is carried out from a standing position due to greater mobility that such position provides. In that way, the arms can reach commands more easily and perform actions.

II. To avoid injuries, the head must be kept in a vertical position, short breaks of 2 to 10 seconds must be made at every 2 or 3 minutes and the repetition of movements must be reduced to 2000 per hour. 
III. At last, it is recommended that the angle of comfort for the circular movement of the arm forward is of $45^{\circ}$ between the peduncle and the worker's hand, in order to get the most of the worker's strength and to reduce health damages.

For an effective improvement of the extraction task it was necessary to change the worker's posture as much as the tool used, for as the posture was considered inadequate, the tool used for the extraction is also inappropriate for the task and needs to undergo modifications in order to have its performance improved and to reduce damages to the worker's health.

\subsection{Project requirements}

Considering the information achieved by observation of the activity, there have been necessities raised translated as requirements. Figure 14 represents the requirements of users grouped according to performance, safety and comfort.

From the result of the research it was also possible to create requirements for the product such as (Figure 15).

Based on the requirements listed, a conceptual model is presented in Figures 16 and 17 for a extraction tool.

The conceptual model for a extraction tool will serve as basis for the development of task efficiency and efficacy improvements as much as for the reduction of injuries for the users.

\subsection{Ambience}

To compare the use of the actual tool with that of the conceptual one, a virtual ambience was proposed with the purpose of simulating the use of both tools on the three stages: cutting of the upper packs, cutting of the middle packs and the cutting of the lower packs of bananas.

Figure 18 represents the ambience with postures while the actual tool is used. As it was previously analysed, postures for the cutting stages with the use of this tool are of classes 1, 2 and 3, according to the OWAS system.

In comparison with postures while using the former tool, the conceptual tool proposed presents improvements in this question, displayed in Figure 19. For the analysis of the OWAS system, the posture for cutting the higher packs with the conceptual tool is of class 1 , for it presents the back straight, one arm upwards and both legs straight. As for the cutting of the middle packs the posture is of class 2 , for it is carried out with the back inclined, both arms downwards and both legs slightly flexed. From the OWAS analysis posture improvements have been noticed for the cutting of packs at both ends of the bunch (upper end and lower end), which were detected as class 3 upon use of the previous tool and have been replaced by postures of classes
1 and 2 with the new tool. On the other hand, the posture for cutting the middle packs did not change, due to the fact that it was less damaging (class 2) and that it had the better out of the cutting as it was in the zone where the user had an optimum reach.

The tool proposed also showed benefits regarding its vertical handle, for it allowed a more comfortable position for the user, with a neutral position of the wrist (when the palm of the hand is turned, the side of the body and the elbow joint is flexed), which reduced the excessive raising the flexed elbow joint on the cutting of higher and middle packs. The vertical holding also reduced the inclination angle of the user's back during the task, for it made it easier to insert the tip of the blade for a cutting close to the peduncle and for better reaching the packs. In that way,

\begin{tabular}{|c|c|}
\hline & User Requirements \\
\hline & Cutting ability \\
\hline & Agility to put the blade in the peduncle \\
\hline & Cutting ability \\
\hline & Cutting maintenance \\
\hline 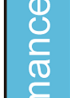 & $\begin{array}{l}\text { Facilitate the cutting for the next banana } \\
\text { pack }\end{array}$ \\
\hline 은 & Facilitate the access to lower packs \\
\hline 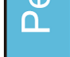 & Facilitate the access to higher packs \\
\hline & Separate individual banana packs \\
\hline & $\begin{array}{l}\text { Enable the use with one hand holding } \\
\text { the pack and the other one controling } \\
\text { the tool }\end{array}$ \\
\hline$\frac{\lambda}{4}$ & Handle distanced from the blade \\
\hline $\mathcal{N}$ & Handle with grip \\
\hline & Comfortable handle \\
\hline & Reduced pressure areas \\
\hline & $\begin{array}{l}\text { Reduce the postures of class } 3 \text { for class } \\
1 \text { (normal) and class } 2 \text { (lower risk) }\end{array}$ \\
\hline ○ & $\begin{array}{l}\text { Reduce the postures of class } 3 \text { for class } \\
1 \text { (normal) and class } 2 \text { (lower risk) }\end{array}$ \\
\hline & $\begin{array}{l}\text { Reduce abduction, flexion, extension, } \\
\text { twisting and pronation of upper limbs }\end{array}$ \\
\hline
\end{tabular}

Figure 14. Users requirements. Source: The authors. 


\begin{tabular}{|c|c|}
\hline & Product Requirements \\
\hline & $\begin{array}{l}\text { (a) Maintainance of the blade curvature } \\
\text { (standardized accordidng to the diameter } \\
\text { of the peduncle) }\end{array}$ \\
\hline हᄐํㅇ & $\begin{array}{l}\text { (b) Increase the angle of the blade to } \\
\text { reduce twisting of the upper limb }\end{array}$ \\
\hline ᄃ & $\begin{array}{l}\text { (c) Increase the blade lenght to follow } \\
\text { the increased angulation }\end{array}$ \\
\hline 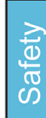 & $\begin{array}{l}\text { (d) Larger diameter at the ends of the } \\
\text { handle to prevent it from slipping out of } \\
\text { the hand during use }\end{array}$ \\
\hline & (e) Geometric handle \\
\hline & $\begin{array}{l}\text { (e) Size of the handle based on } \\
\text { anthropometric measurements (male } \\
\text { percentile } 95 \% \text { ) }\end{array}$ \\
\hline 0 & $\begin{array}{l}\text { (e) Vertical handle that facilitates the } \\
\text { entrance of the tip of the blade on the } \\
\text { peduncle and allows the neutral position } \\
\text { of the wrist }\end{array}$ \\
\hline
\end{tabular}

Figure 15. Product requirements. Source: The authors.

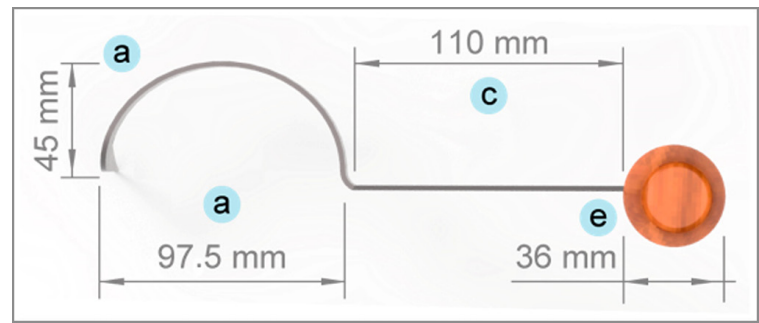

Figure 16. Conceptual model of the extraction tool from a top perspective. Source: The authors.

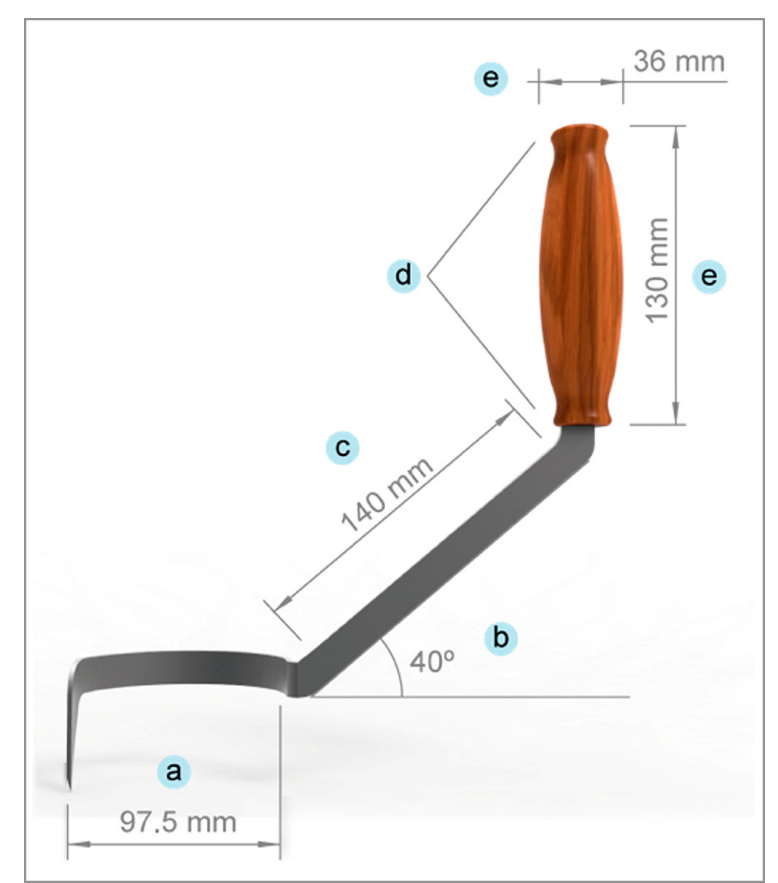

Figure 17. Conceptual model of the extraction tool from a frontal perspective. Source: The authors.

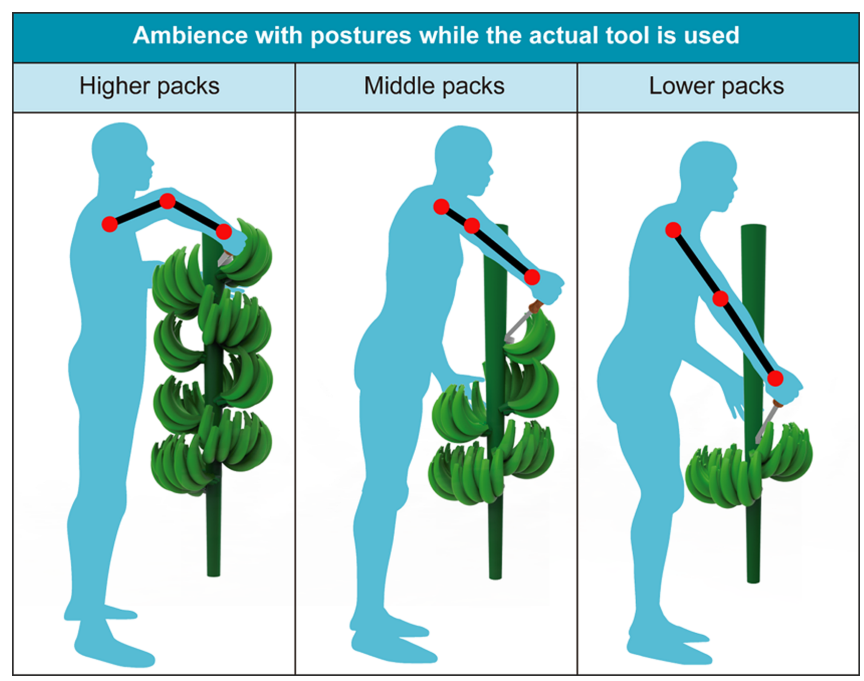

Figure 18. Ambience with postures while the actual tool is used. Source: The authors.

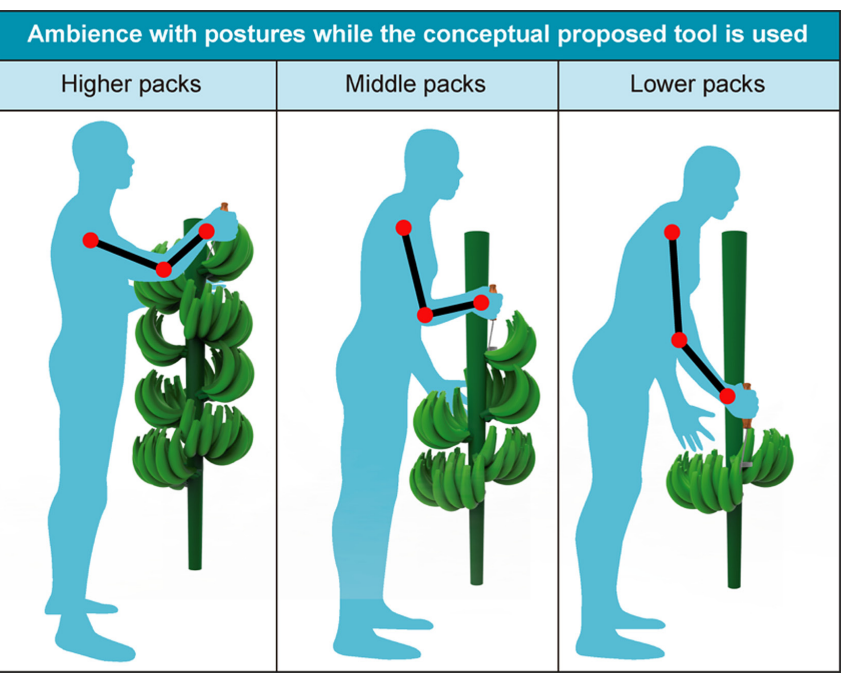

Figure 19. Ambience with postures while the conceptual proposed tool is used. Source: The authors.

the ambience has has proved that the conceptual tool, on simulation, has improved the posture of the worker abd increased its efficiency and efficacy upon completion of the task and on extraction.

\section{Conclusion}

From the analysis of the banana extraction task in the system OWAS, it has been observed that the activity offers great posture risks worthy of attention. Fir most of the task the worker is subject to posture constraints of class 3 , which need to be replaced by less harming postures of classes 1 and 2. For such an improvement, the project for a new conceptual tool, based on requirements established with the observation of pack extraction has shown to be necessary to change those inconvenient postures. 
The ambience of the new tool has proved an improvement of the class 3 postures for the cutting of banana packs at both ends of the banana bunch carried out with the new tool changing them to classes 1 and 2 postures with less damaged to the worker's health.

On the other hand, class 2 postures have been maintained, such as the cutting of middle packs, for they were less health damaging and they are related to an optimum reach by the user. From the ambience it was also possible to observe that a holding position change in the tool has improved its performance and reduced the user's posture constraints.

However, apart from the tool, other factors can also influence the worker's posture, such as the length of the workday, the height of the packs at both ends of the bunch and the worker's habit of projecting the same movements for cutting the packs, for the activity speed and the repetition of movements aggravates the posture risks and constraints. In that way, in order to achieve significant improvements on the extraction task, it is necessary to link the development of the new tool with readjustment of work and of the worker.

\section{Acknowledgements}

To the Higher Education Personnel Improvement Coordination (CAPES), to the National Council for Scientific and Technological Development (CNPq), to the a Foundation of Support to Research and Innovation in the State of Santa Catarina (FAPESC), to the Agricultural Research Corporation and Rural Extension of Santa Catarina (Epagri), the producer of bananas Cooper River New Corupá-SCand to the Design Management Center (NGD/UFSC) who have made this research possible.

\section{References}

ARAGUAIA, M. Banana. 2014. Available from: <http:// www.brasilescola.com/frutas/banana.htm>. Access in: 13 Aug 2014.

BORGES, A. L. et al. Colheita e pós-colheita. 2014. Available from: <http://sistemasdeproducao.cnptia.embrapa.br/
FontesHTML/Banana/SistemaOrganicoCultivoBanana/ colheita.htm>. Access in: 4 Dec 2014.

DREYFUSS, H.; TILLEY, A. R. As medidas do homem e da mulher. Porto Alegre: Bookman, 2005.

EMPRESA BRASILEIRA DE PESQUISAAGROPECUÁRIA - EMBRAPA. Produção nacional de banana. 2013. Available from: <https://www.embrapa.br/ documents/1355135/1905644/b1_banana.pdf/6c38c3340fb6-4cd6-9fe3-43d2b1aada24>. Access in: 22 Aug 2014.

FLEMING, I. Diagnóstico ergonômico preliminar em comunidade agrícola com produção diversificada. Florianópolis: UFSC, 2003.

HALL, S. J. Biomecânica básica. 5. ed. Barueri: Manole, 2009.

HAMILL, J.; KNUTZEN, K. M. Bases biomecânicas do movimento humano. 3. ed. Barueri: Manole, 2012.

IIDA, I. Ergonomia: projeto e produção. São Paulo: Blucher, 2005.

INTERNATIONAL ERGONOMICS ASSOCIATION - IEA. Definition and domains of ergonomics. 2000. Available from: <http://www.iea.cc/whats/index.html>. Access in: 9 Jan 2015.

KAPANDJI, I. A. Fisiologia articular: esquemas comentados de mecânica humana. 5. ed. Rio de Janeiro: Editorial Médica Panamericana, 2000. v. 1.

MOnTEiro, J. C. O Processo de trabalho no desencadeamento dos agravos à saúde dos trabalhadores rurais: um estudo ergonômico na agricultura familiar em Santa Catarina. Florianópolis: UFSC, 2004.

Silva NETO, S. P.; GUIMARÃES, T. G. Evolução da cultura da banana no Brasil e no mundo. Planaltina: Embrapa Cerrados, 2011. Available from: <http://www. cpac.embrapa.br/noticias/artigosmidia/publicados/287/>. Access in: 17 Oct 2014. 